\title{
POLÍTICAS ESTATALES PARA LAS INSTITUCIONES Y EL ARTE ARGENTINO EN LOS AÑOS ' $30^{1}$
}

\author{
State policies for Argentine art and Institutions in the 1930s
}

\begin{abstract}
Patricia Basualdo*
https://orcid.org/0000-0002-1857-7436

\section{Resumen}

Durante los años treinta del siglo XX, el Estado nacional a través de la Dirección Nacional de Bellas Artes (DNBA) desarrolló diversos proyectos que tuvieron como finalidad difundir e incentivar la producción de arte argentino en el país y descentralizar las actividades artísticas que se anclaban en la ciudad de Buenos Aires. Fue en este sentido que creó la Federación de Comisiones Oficiales de Bellas Artes (1934-1936) y se organizaron las exposiciones viajeras con las obras premiadas en el Salón Nacional de Bellas Artes (SNBA) (1934-1937). Estas iniciativas se sumaban a la política de préstamos de obras que el Museo Nacional de Bellas Artes (MNBA) venía practicando desde la primera década del siglo para fundar museos o complementar la colección de los de reciente creación en distintas ciudades provinciales.

Este artículo se propone exponer la puesta en marcha de los mencionados programas, revelar los conflictos que se desencadenaron a su alrededor, comparar la composición de los envíos fundacionales a las ciudades bonaerenses para determinar la presencia del arte argentino en su armado y establecer, por un lado, si la difusión de las producciones plásticas del país fueron prioridad en cada uno de ellos y, por el otro, el lugar que ocuparon los espacios provinciales y sus artistas en los programas de proyección nacional.
\end{abstract}

$<$ Década de 1930><Arte Argentino > < Instituciones Artísticas $>$

\begin{abstract}
During the 1930s, the Federal Government, through the Dirección Nacional de Bellas Artes (DNBA), developed several projects that aimed to propagate and encourage the production of Argentine art within the country and to decentralize art activities anchored in Buenos Aires. For this reason, the Federación de Comisiones Oficiales de Bellas Artes (1934-1936) was created and traveling exhibitions were organized with award-winning works at the Salón Nacional de Bellas Artes (SNBA) (1934-1937). These efforts added to the works loan policy that the Museo Nacional de Bellas Artes (MNBA) had deployed since the first decade of the century for the foundation of museums, or to supplement the collections of recently created museums in different provincial cities.

This paper intends to describe the implementation of the above-mentioned programs, reveal the conflicts that arose from them, and compare the configuration of first deliveries to cities across Buenos Aires to determine the presence of Argentine art in their layout; it also intends to establish, on the one hand, if the promotion of national artistic works was critical in each of them and, on the other hand, the place taken up by provincial exhibition halls and their artists in those programs of national impact.
\end{abstract}

$$
<1930 \text { s }><\text { Argentine art }><\text { artistic institutions }>
$$

Recibido: 09/12/2020 // Aceptado: 12/05/2021

${ }_{1}^{1}$ El presente artículo se enmarca en la investigación doctoral sobre el proceso de formación de los primeros museos municipales de arte en la provincia de Buenos Aires en las décadas del treinta y cuarenta.

* Doctoranda en Historia, Instituto de Altos Estudios Sociales (IDAES), Universidad Nacional de San Martín (UNSAM), Buenos Aires, Argentina, pbasualdo@unsam.edu.ar 


\section{Contactos entre instituciones municipales y organismos públicos nacionales}

En la década de 1930 comenzaron a hacer su aparición los municipales de arte en la provincia de Buenos Aires. Bahía Blanca fue la ciudad precursora en celebrar salones de este tipo y también en inaugurar un museo municipal de arte, en 1931. Luego le siguieron los salones de Pergamino, en 1934, y los de Tandil desde 1938. En esta última localidad el Museo Municipal de Bellas Artes se había inaugurado un año antes, mientras que en Pergamino el Museo se abrió en la década siguiente. Además, en los primeros años del período que nos ocupa, en San Nicolás de los Arroyos se realizaron gestiones para tener una institución de este tipo, pero nunca llegó a concretarse.

Las comisiones municipales de bellas artes, que estuvieron a cargo de estas iniciativas, encontraron en los programas de los organismos nacionales, como la Dirección Nacional y el Museo Nacional de Bellas Artes, una manera de vincularse con las actividades artísticas que sucedían en la Capital Federal y, también, una forma de sostener y de fortalecer sus proyectos locales. El tema abordado en este artículo está relacionado con el interés de establecer el contexto en el cual surgieron estas nuevas instituciones locales y con problematizar la agencia de los organismos estatales en los procesos que estudiamos. En este sentido, nos enfocamos en el rol que desempañaban las entidades públicas en esta década y en reponer las propuestas que se impulsaron para las instituciones del "interior" del país. En relación a esto último, nos interesa exponer las distancias experimentadas entre lo enunciado por los discursos oficiales y la puesta en marcha de los programas nacionales en las localidades implicadas.

El material documental utilizado para este artículo fue consultado en archivos y bibliotecas púbicas en la ciudad de Buenos Aires y en las localidades de Bahía Blanca, Tandil y Pergamino ${ }^{2}$. Los espacios de la ciudad capital nos proporcionaron documentos y publicaciones sobre los proyectos del Estado Nación en materia artística y, también, nos permitieron reconstruir algunas de las críticas expresadas por personalidades destacadas dentro del campo artístico porteño, en términos de Pierre Bourdieu (1990). En las ciudades bonaerenses, la consulta de la prensa local en las hemerotecas públicas fue clave para reconstruir la puesta en marcha de las políticas estatales. Además, el acceso a las actas de la Comisión Municipal de Bellas Artes, que se conservan en el Museo de arte de Pergamino, fue un hallazgo excepcional muy valioso, ya que el resto de las instituciones locales no conservan documentación correspondiente al período relevado.

El aporte teórico de Irina Podgorny (2005) ha sido fundamental para reflexionar y reconsiderar el modo de estudiar la conformación de los museos y de las instituciones públicas. Sus investigaciones han abierto una nueva mirada sobre estos espacios, apartándose de la idea de museo como herramienta mediante la cual el Estado-Nación instala determinados saberes y conceptos con la finalidad de legitimar su poder. Su enfoque, en cambio, ilumina las prácticas que están por detrás de las intenciones que se reflejan en los discursos oficiales, las cuales terminan por definir la apertura (o no) de

\footnotetext{
2 En la ciudad de Buenos Aires se consultaron: el archivo del Palais de Glace, la Biblioteca Nacional Mariano Moreno, el archivo de la Fundación Espigas, el archivo Mario A. Canale, la biblioteca y archivo del MNBA, y el Fondo Eduardo Schiaffino, alojado en el Archivo General de la Nación.
} 
instituciones, la conformación de las colecciones públicas y los objetos de estudios de las disciplinas científicas. Esta perspectiva, nos permite contraponer el relato oficial con las dinámicas propias de cada caso y exponer las particularidades que se enfrentaron en el camino hacia la institucionalización de los espacios artísticos bonaerenses seleccionados. En este sentido, la desacralización del rol del Estado y el foco en los conflictos, complejizan el desarrollo y la correspondencia, que se supone lineal, entre las prácticas sancionadas por la DNBA y el MNBA y su implementación en las ciudades bonaerenses. Este fue el enfoque que orientó los resultados que compartimos en este artículo.

\section{Una mirada hacia el "interior": la Federación de Comisiones Oficiales de Bellas Artes}

El Estado Nacional de los años treinta se caracterizó por asumir nuevas funciones, con un fuerte interés en la obra pública y en la creación de nuevas instituciones sociales y culturales. Los ministerios de Obras Públicas y de Instrucción Pública experimentaron una etapa de gran expansión respecto a sus competencias. El primero se abocó a la tarea de modernizar la infraestructura del territorio argentino y a compensar el nivel de desarrollo de las diversas regiones respecto a la ciudad capital a través de la construcción de nuevas rutas y la extensión y modernización de las vías férreas (Ballent y Gorelik, 2001). Por su parte, el Ministerio de Justicia e Instrucción Pública, además de profundizar la acción educativa, introdujo nuevos organismos orientados a distinguir y a preservar los valores históricos, sociales y culturales del "interior" del país (Cattaruzza, 2001). Fue en esta década que se crearon la Dirección de Parques Nacionales (1934), la Comisión Nacional de Museos y de Monumentos y Lugares Históricos (1938), que incorporó instituciones como los Museos Históricos (Sarmiento y Mitre) y la Comisión Nacional de Bellas Artes (CNBA) la cual entre 1931 y 1938 fue reemplazada por la Dirección Nacional de Bellas Artes (DNBA).

La CNBA había sido creada en 1897. Inicialmente, su principal función estaba vinculada a la reglamentación, administración y otorgamiento de becas para artistas que buscaban formarse en el exterior. A partir de 1907 incorporó bajo su injerencia a la Academia (nacionalizada en 1905) y al Museo Nacional de Bellas Artes. Desde 1911, también se ocupó de la organización del Salón Nacional de Bellas Artes (Herrera, 2014, p. 57) y más adelante, sumó los espacios de enseñanza artística, como la Escuela de Artes Decorativas, la Escuela Nacional de Arte y la Escuela Superior de Bellas Artes (Gutiérrez Viñuales, 2004, pp. 110-111). Es decir que, hacia inicios de los años treinta, tenía a su cargo las instituciones artísticas oficiales más importantes del país y consolidaba su posición dentro del campo artístico nacional.

La DNBA se propuso continuar con las tareas que venía realizando el organismo predecesor. Esto es, coordinar y supervisar las actividades e instituciones públicas de todo el país y agregó como objetivo: "fomentar la instalación de Comisiones en las provincias con los mismos propósitos que la Dirección Nacional"3. Fue con esta aspiración que el ingeniero Nicolás Besio Moreno, director de la DNBA, incitó a los

3 Uriburu, J. F. (1 de septiembre de 1931). Exp. M. 144/1931 [decreto de creación de la DNBA]. Ministerio de Justicia e Instrucción Pública. Archivo CNBA, Buenos Aires. 
gobernadores provinciales a que organizaran sus propias comisiones de Bellas Artes, a nivel provincial o municipal, con la premisa de que las autoridades públicas debían ayudar al número cada vez más amplio y prestigioso de artistas activos en el país "haciendo conocer la obra de los artistas para loa de éstos y educación del pueblo"".

Bajo este espíritu, la DNBA se atribuyó la creación de las comisiones de Chascomús, Pergamino, San Nicolás, Tandil, Catamarca, San Francisco (Córdoba), Concepción del Uruguay, Gualeguaychú, Jujuy, La Rioja, Mendoza, Salta, Santiago del Estero, Tucumán y Posadas, que se sumaban a otras siete ya existentes ${ }^{5}$. Sin embargo, sabemos que las comisiones de Tandil (Suasnábar, 2013) y de Pergamino, creadas en 1936 y 1934 respectivamente, nacieron a partir del interés de los agentes locales, quienes luego se acercaron al organismo nacional y no al revés, lo cual nos habilita a poner en duda su participación en el resto de los casos. De todos modos, ambas comisiones recibieron el apoyo de la DNBA, sobre todo la de Tandil, a donde envió un conjunto de obras del MNBA para fundar el Museo Municipal, a fines del año 1936.

Otra de las innovaciones de la DNBA para fortalecer el arte por fuera de la capital, fue la creación de la Federación Nacional de Comisiones Oficiales de Bellas Artes en 1934. Esta entidad estaba presidida por el director de la DNBA, acompañado por un Consejo Directivo, con sede en la ciudad de Buenos Aires. En rasgos generales, se proponía coordinar la actividad de las comisiones de bellas artes del país con reuniones anuales de todos sus representantes. La DNBA señaló que en estas sesiones se aprobaron "numerosas mociones de gran interés para la coordinación y difusión de las bellas artes en su aspecto cultural y docente y la protección del acervo artístico y arqueológico del país"6. Anteriormente, había destacado las gestiones realizadas en favor de los artistas, tales como facilitar pasajes de FFCC, proveer materiales y útiles y liberar derechos de Aduana $^{7}$. Sin embargo, no tenemos información sobre la ejecución de estas iniciativas. Presumimos, en cambio, que su actuación se limitó a organizar los encuentros anuales, desde su creación hasta 1936. Fue por este motivo que la Comisión Municipal de Bellas Artes de Pergamino, al advertir que la Federación solo tenía existencia real en esos eventos, resolvió enviar directamente la información referida a sus actividades al presidente de la DNBA, que por ese entonces era Antonio Santamarina ${ }^{8}$. Estimamos que, para el año 1938, la Federación había quedado sin efecto y que su disolución estaba ligada a la falta de un programa y de una organización por fuera de las sesiones anuales.

${ }_{4}^{4}$ Besio Moreno, N. (septiembre y octubre de 1934). Propiciase la creación de comisiones de bellas artes en el interior. En Boletín del Museo Nacional de Bellas Artes, p. 21.

5 DNBA, (1 de septiembre 1931 - 8 de marzo 1938). Cuarta época. Archivo Palais de Glace, Buenos Aires. El documento dice que son 17 pero solo enumera 15 nuevas comisiones Las comisiones que ya existían eran las de La Plata, Rosario, Córdoba, Bahía Blanca, Santa Fe, Paraná y la CNBA.

6 DNBA, (1 de septiembre 1931 - 8 de marzo 1938). Cuarta época. Archivo Palais de Glace, Buenos Aires.

7 Ministerio de Justicia e Instrucción Pública (1934). Museos y Comisiones de Bellas Artes del Interior. En: Dirección Nacional de Bellas Artes. Organización y funcionamiento, Buenos Aires, p. 15. Biblioteca Nacional Mariano Moreno.

8 CMBA de Pergamino (30 de junio de 1938). Libro de Actas. Escuela Municipal de Bellas Artes (19361940). Archivo del Museo Municipal de Artes Plásticas "Manuel Belgrano" de Pergamino. 
Aun así, el presidente de la Comisión de Pergamino, Enrique Martínez Granados, valoró el accionar de este organismo al manifestar que gracias a ella fue posible la vinculación entre las comisiones diseminadas en todo el territorio de la Nación y que el día de mañana esto permitiría "la floración del arte nacional que aún no existe y que

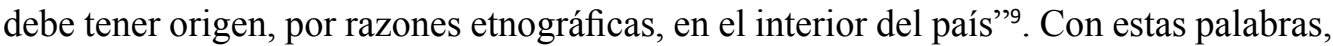
llamaba la atención sobre una cuestión que los representantes de las provincias iban a reclamar en otras oportunidades: la construcción de un arte nacional que contemplase las producciones plásticas de artistas que no frecuentaban los circuitos capitalinos. Esta y otras diferencias salieron a la luz cuando la DNBA continuó con los préstamos fundacionales con obras del MNBA e inició las exposiciones con los premios del Salón Nacional de Bellas Artes (SNBA).

Por lo tanto, el limitado funcionamiento de la Federación y la falta de interés por instalar a los artistas provinciales en el campo artístico capitalino, no solo que no favoreció a la consolidación de los espacios locales y a la difusión de sus producciones, sino que terminaron operando como estrategias indirectas para fortalecer el carácter paternalista que ostentaba el organismo nacional.

\section{De viaje por las provincias: las exposiciones con los premios del Salón Nacional}

Las giras con los premios del SNBA tuvieron lugar en cuatro oportunidades, entre 1934 y 1937. Cada una realizó recorridos diferentes, atravesando gran parte del territorio. Veinte fueron las localidades que alojaron esta exposición, entre capitales y ciudades provinciales. Pero, a excepción de Río Cuarto, solo las ciudades cabeceras recibieron la exposición en más de una oportunidad. Entre estas últimas se encontraban las capitales del noroeste y del centro del país, las cuales recibieron casi con regularidad los premios del Salón desde 1935 hasta la finalización del programa (Figura 1). Ambas regiones eran visitadas con especial atención por intelectuales, críticos de arte $\mathrm{y}$ artistas desde los primeros años del siglo $\mathrm{XX}$, tendencia que se profundizó en la década del veinte cuando las temáticas nativistas -relacionadas con el paisaje andino, serrano o pampeano, y las figuras del indígena del altiplano, el gaucho del litoral o los campesinos españoles- comenzaron a aparecer con mayor frecuencia en los discursos y representaciones plásticas $\mathrm{y}$, con ello, la valorización de esas regiones para la configuración del imaginario nacional (Fasce, 2017, pp. 17-26). Como contrapartida, otras regiones aún estaban fuera del rango de consideración, como fue el caso de las provincias patagónicas que continuaban siendo territorios por explorar ${ }^{10}$.

\footnotetext{
9 Martínez Granados, E. (8 de noviembre de 1938). Consideraciones con respecto al V Salón Municipal de Bellas Artes. La Opinión, Pergamino, p. 5.

${ }^{10}$ Nos referimos a las provincias de Río Negro, Santa Cruz, Chubut y Tierra del Fuego. Es importante señalar que junto a las de Chaco, Formosa, Misiones y La Pampa, en ese momento y desde 1884 eran parte de los territorios nacionales.
} 
Basualdo. Políticas estatales para las instituciones y el arte argentino en los años '30.

Figura 1. Recorrido de las exposiciones viajeras entre 1934 y 1936

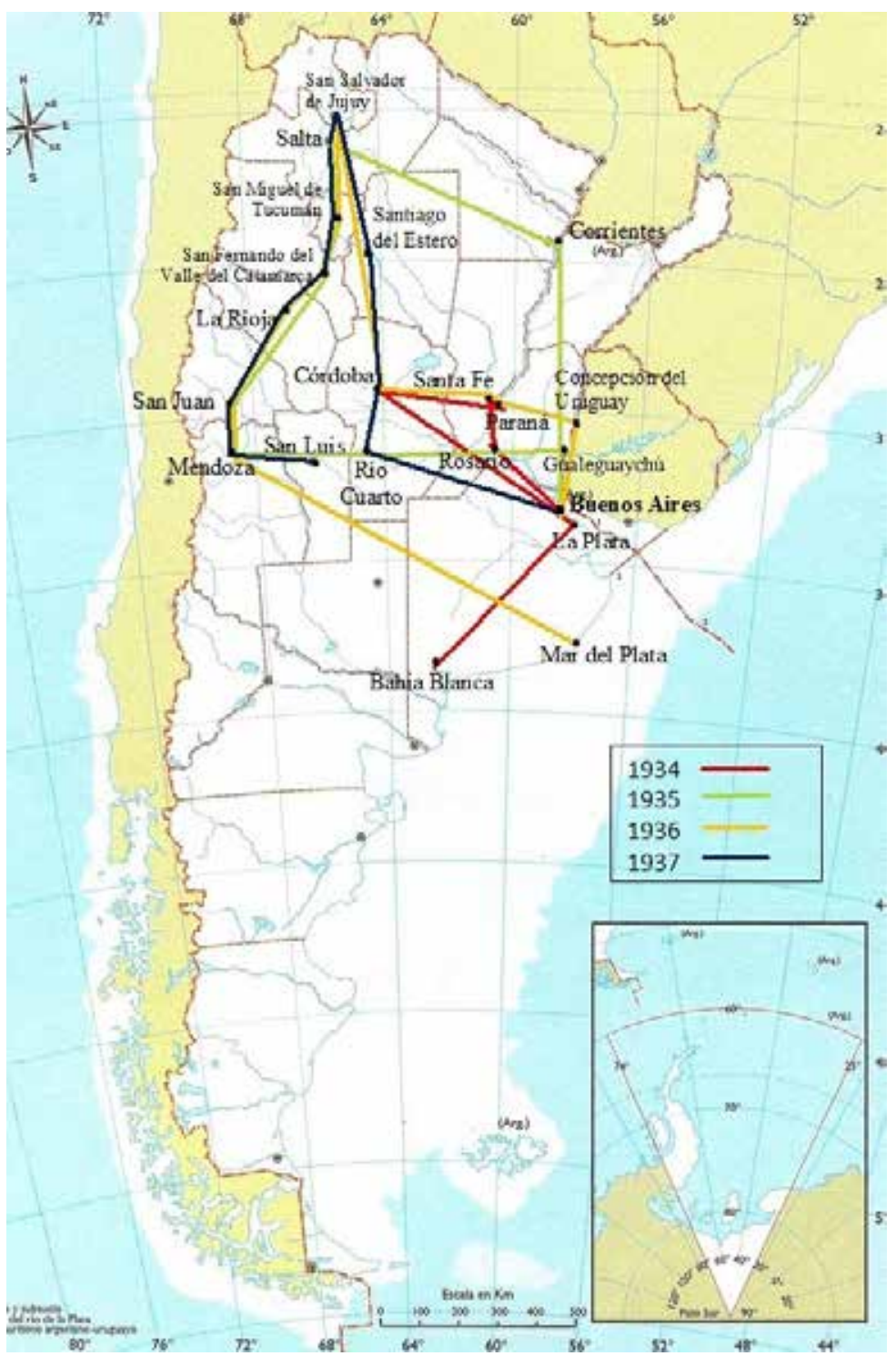

Fuente: Elaboración propia.

No obstante, no tenemos elementos para atribuir a esta planificación una intencionalidad política o de otro tipo. Esta organización parecía obedecer más a cuestiones prácticas y de decisiones tomadas sobre la marcha, antes que a un plan riguroso donde se estipulara el recorrido o los criterios para llevar las exposiciones a determinadas ciudades, teniendo en cuenta que hubo ciudades que la recibieron hasta tres veces seguidas y otras una vez o directamente nunca (Figura 2). 
Figura 2. Exposiciones viajeras por año y ciudad

\begin{tabular}{lllll}
\hline \multicolumn{1}{c}{ Ciudad } & 1934 & 1935 & 1936 & 1937 \\
\hline Rosario & $\mathrm{X}$ & & & \\
\hline Santa Fe & $\mathrm{X}$ & $\mathrm{X}$ & $\mathrm{X}$ & \\
\hline Paraná & $\mathrm{X}$ & & $\mathrm{X}$ & $\mathrm{X}$ \\
\hline Córdoba & $\mathrm{X}$ & $\mathrm{X}$ & & \\
\hline Bahía Blanca & $\mathrm{X}$ & & & \\
\hline La Plata & & $\mathrm{X}$ & & $\mathrm{X}$ \\
\hline Corrientes & & $\mathrm{X}$ & $\mathrm{X}$ & $\mathrm{X}$ \\
\hline Salta & $\mathrm{X}$ & $\mathrm{X}$ & $\mathrm{X}$ \\
\hline Tucumán & $\mathrm{X}$ & $\mathrm{X}$ & $\mathrm{X}$ \\
\hline Catamarca & $\mathrm{X}$ & $\mathrm{X}$ & $\mathrm{X}$ \\
\hline San Juan & $\mathrm{X}$ & & \\
\hline Mendoza & $\mathrm{X}$ & & $\mathrm{X}$ \\
\hline Río Cuarto & $\mathrm{X}$ & $\mathrm{X}$ & $\mathrm{X}$ \\
\hline Gualeguaychú & & $\mathrm{X}$ & $\mathrm{X}$ \\
\hline Concepción del Uruguay & & $\mathrm{X}$ & $\mathrm{X}$ \\
\hline La Rioja & & & \\
\hline Jujuy & & & \\
\hline Mar del Plata & & & \\
\hline Santiago del Estero & & & \\
\hline San Luis & & & \\
\hline
\end{tabular}

Fuente: Elaboración propia.

En este aspecto, sabemos que, para que la exposición se concretara, era fundamental que los organismos locales colaboraran para tal fin: disponer y acondicionar un espacio para la exposición $\mathrm{y}$, sobre todo, costear los gastos que contraía este despliegue ${ }^{11}$. En general, se montaban en lugares que prestaba la municipalidad de cada localidad. Muchas veces era el mismo espacio donde funcionaba el museo de arte, como fueron los casos de Bahía Blanca y de Río Cuarto ${ }^{12}$. En Mar del Plata, se destinó para su montaje el salón de conferencias del Club homónimo, ya que aún no contaba con una institución de este tipo ${ }^{13}$. Otro ejemplo notorio de la relevancia de las comisiones locales es el catálogo del Museo de Bellas Artes de Río Cuarto, dedicado a la exposición con las obras premiadas en el XXVII Salón Nacional de Artes Plásticas (Figura 3). Esta publicación nos hace suponer que la edición de un catálogo o folleto también corría por cuenta de las comisiones o museos que solicitaban la exposición, mientras que la DNBA parece haberse ocupado solo del catálogo correspondiente a la primera edición (Figura 4).

${ }^{11}$ Dirección Nacional de Bellas Artes (septiembre y octubre de 1934). Boletín del Museo Nacional de Bellas Artes, p. 20-21.

${ }^{12}$ En esta época, el Museo Municipal de Bellas Artes de Bahía Blanca, funcionaba en una sala del Club Argentino; Exposición de obras del Salón Nacional (1 de enero de 1935). La Nueva Provincia, Bahía Blanca.; Museo de Bellas Artes, Palacio Municipal, Exp. Cat., Río Cuarto, diciembre - enero. Archivo Fundación Espigas, Buenos Aires.

${ }^{13}$ Una muestra de arte se realizará en Mar del Plata (4 de febrero de 1937). La Capital, Mar del Plata. 
Figura 3. Catálogo de la exposición con los premios del XXVII SNBA en el Museo Municipal de Bellas Artes de Río Cuarto, Córdoba, diciembre-enero de 1937
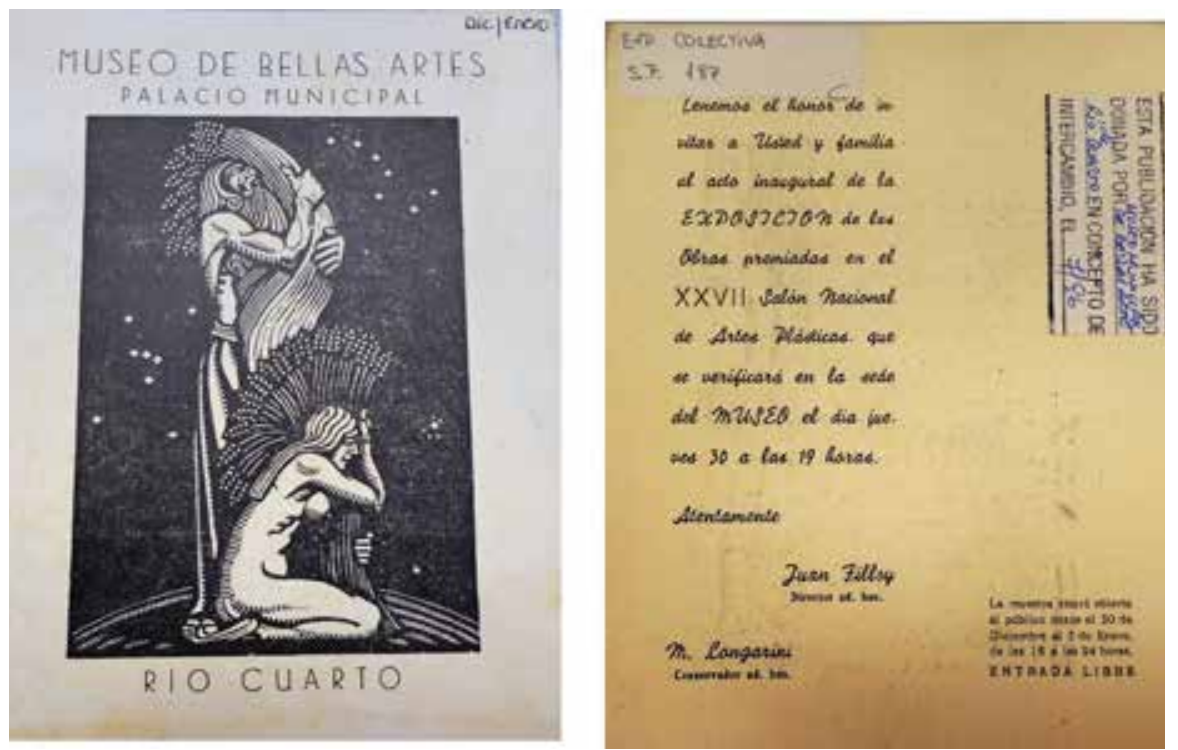

Fuente: Colección Centro de Estudios Espigas. Fundación Espigas.

Figura 4. Catálogo de la primera exposición de premiados en el Salón Nacional de Bellas Artes, gira del 1934

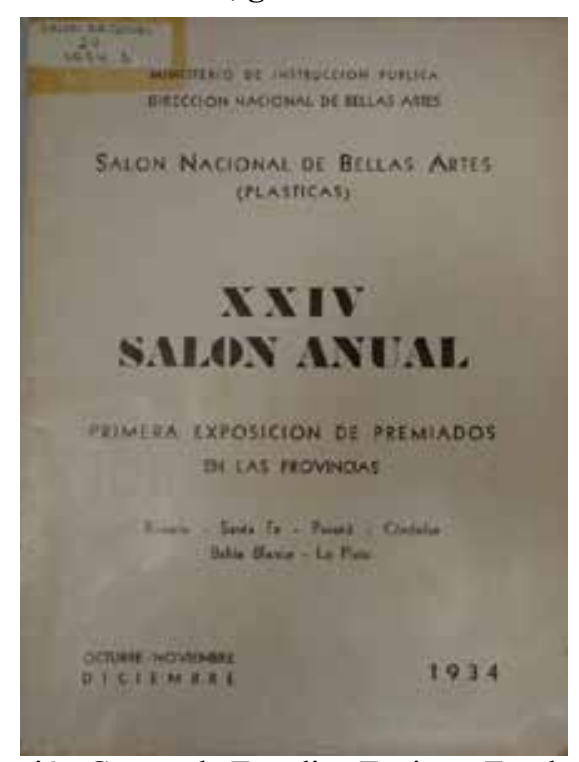

Fuente: Colección Centro de Estudios Espigas. Fundación Espigas.

Para sortear las dificultades económicas que atravesaban los organismos locales, en la reunión de la Federación de Comisiones Oficiales de 1935, se había resuelto que las comisiones que habían recibido la exposición el año anterior-Rosario, 
Santa Fe, Paraná, Córdoba, La Plata y Bahía Blanca - también costearan la gira de ese año, "para que no se interrumpa la nueva serie de exposiciones organizada en el país"14. Desconocemos si efectivamente esta exposición se realizó con el aporte de estas comisiones, a la vez que dudamos que este espíritu de solidaridad se haya sostenido en el tiempo, a la luz de lo sucedido en Pergamino. El presidente de esta Comisión, Enrique Martínez Granados, rechazó la exposición en 1936 porque no podían sufragar el gasto de $\$ 500$, aun reconociendo los "grandes beneficios" que significaba para las ciudades de tierra adentro esa muestra del arte naciona ${ }^{15}$. Solo en diciembre de 1938 lograron conseguir los fondos requeridos y, en esa oportunidad, Martínez Granados resaltó que el ambiente artístico de Pergamino se hacía de una herramienta para conseguir "su consagración definitiva en el exterior" 16 . Sin embargo, a pesar de lo dicho, hasta donde tenemos conocimiento, esta exposición no llegó a concretarse.

De todos modos, es necesario señalar que la anhelada consagración era para la Comisión Municipal, no para los artistas pergaminenses: la visita del arte de la capital no contemplaba la exhibición de sus obras y, como veremos a continuación, tampoco era frecuente su llegada al Salón Nacional.

\section{Las críticas al Salón Nacional de Bellas Artes desde el "interior"}

Cuando se iniciaron las exposiciones viajeras con las obras premiadas, en 1934, el Salón Nacional ya contaba con más de veinte años de trayectoria y se había convertido en una importante institución para la configuración y consolidación del arte argentino y un catalizador para su comercio (Baldasarre, 2011, p. 251). La bibliografía sobre este concurso ya se ha referido a las críticas que venía enfrentando desde su creación, en relación con la tendencia conservadora que caracterizaban los dictámenes del jurado y a los pocos cambios que había en la composición de sus miembros (Wechsler, 1998; 1999). Con el programa de difusión de sus premios, no solo circularon las obras legitimadas por esta institución; también se avivaron esas críticas sobre el concurso y se cosecharon otras nuevas.

Una de ellas fue la del artista Mario A. Canale ${ }^{17}$. Desde su cargo como secretario en la Comisión Provincial de Bellas Artes de La Plata, y a través de la revista Momento Plástico, se encargó de denunciar, entre otras cosas, el enviciamiento que existía entre los miembros de la Dirección y los artistas que participaban en el Salón:

Hay miembros de Comisión que modelan, su obra es de aficionados, y expanden su producción fructífera en el país. No hay derecho de ejercer puestos espectables (sic.) en el orden artístico y producir obra que por razón de su cargo hasta

\footnotetext{
${ }^{14}$ Se exhibirán en varias provincias los premios del XXV Salón Anual (10 de octubre de 1935). La Nación.

${ }^{15}$ CMBA de Pergamino (26 de agosto de 1936). Libro de Actas. Ob. cit.

${ }^{16}$ CMBA de Pergamino (29 de abril de 1938). Libro de Actas. Ob. cit.

${ }^{17}$ Mario Augusto Canale (1890-1951) fue pintor, grabador, escritor y docente. Estuvo a cargo de la revista Athinae (1908-1911), El grabado (1916) y Momento Plástico (1933). Fue secretario de la Comisión Provincial de Bellas Artes de la provincia de Buenos Aires entre 1932 y 1943.
} 
Basualdo. Políticas estatales para las instituciones y el arte argentino en los años '30.

tienen libre acceso en el Salón Nacional de Bellas Artes cuya exhibición haría sonrojar e irritar a más de un rechazado ${ }^{18}$.

Otra de las voces resonantes sobre este tema fue la del arquitecto Alberto Prebisch $^{19}$. En una de las conferencias que brindó en el MNBA, reconoció el valor que tenía este programa, pero pretendía "que esta acción se extendiese a todas las exhibiciones representativas que se produzcan en Buenos Aires" ${ }^{20}$, puesto que, según su consideración:

nuestras manifestaciones artísticas se remansan en Buenos Aires, y pocas veces llegan a las provincias otra cosa que el lejano eco periodístico de aquéllas. Salvo contadas excepciones, los museos de provincia están formados por desechos de la capital. Su acción cultural es así, peor que nula: es perniciosa ${ }^{21}$.

En la vereda de enfrente se encontraba Atilio Chiáppori ${ }^{22}$. Como ex director del MNBA y protector histórico del SNBA, sostenía que este concurso había contraído múltiples beneficios: no solo había contribuido a que se pueda hablar con orgullo de un arte argentino, sino que también había favorecido a la construcción y difusión de un arte con identidad nacional, y era la base del programa de fundación de museos provinciales (1942, pp.171-180). Esta defensa la hizo extensiva al programa de las exposiciones viajeras ${ }^{23}$, pero aceptó que "dada la heterogeneidad de los jurados y el proselitismo que los afecta, no podría afirmarse de ellas [las obras premiadas] que son los arquetipos del arte argentino". Aun así, consideraba que se había dado el primer paso "en esta novísima y eficaz forma de expansión artística en el interior" (1942, p. 177).

Por fuera de las ciudades capitales, a las críticas mencionadas se sumaba la discusión en torno a las oportunidades que tenían los artistas alejados de la metrópoli de participar en el SNBA. En la reunión de la Federación de 1936, Martínez Granados, como representante de la provincia de Buenos Aires, declaró que el jurado, además de no interpretar "el actual pensamiento estético argentino", excluía de la premiación a los artistas que no habían desarrollado una carrera en la capital nacional. En esa oportunidad,

${ }^{18}$ Canale, M. A. (abril de 1933). Los miembros de la Dirección Nacional de Bellas Artes deben ser técnicos. En Momento Plástico, $\mathrm{n}^{\circ} 1$, año 1, p. 1.

${ }_{19}$ Alberto Prebisch (1899-1970) fue considerado como el precursor de la arquitectura moderna en la Argentina. En la década del '30 desarrolló algunas de sus obras más emblemáticas como el Obelisco de Buenos Aires (1936) y el Cine - Teatro Gran Rex en la misma ciudad (1937).

${ }^{20}$ Museos. Primera conferencia del ciclo, auspiciada por la Asociación Amigos del Museo, a cargo del Arq. Alberto Prebisch. Octubre 18 de 1934 (septiembre y octubre de 1934). Boletín del Museo Nacional de Bellas Artes, p. 2-7.

${ }_{21}$ Boletín del Museo Nacional de Bellas Artes, p. 6.

${ }^{22}$ Atilio Chiáppori (1880-1947) fue secretario del MNBA entre 1911 y 1931 y director entre 1931 y 1939. Fue periodista y crítico literario y de arte en Ideas (1903-1905), en la revista Nosotros (1907-1934 y 1936-1943) y Pallas (1912-1913) y en los diarios La Nación y La Prensa.

${ }^{23}$ Estas exposiciones no recibieron un nombre uniforme. Adoptamos el nombre utilizó Atilio Chiáppori para refiere a una de ellas como "exposición viajera de las obras premiadas en el último Salón Nacional" (1942, p. 177). 
con el apoyo de la mayoría de los participantes, en disidencia con representantes de la Capital Federal"24, se aprobó el proyecto para que la DNBA “arbitrara todas las medidas tendientes a facilitar la mayor representación de los artistas del interior en el Salón Nacional, como también la integración del jurado por personas del interior"25.

Por otra parte, este programa iluminó algunas de las consideraciones que tenían los artistas consagrados sobre los espacios artísticos provinciales. Por las expresiones que Chiáppori volcó en su libro, sospechamos que no todos los premiados en el Salón estaban conformes con este programa. Allí declaró que algunos de ellos, "sin mayor notoriedad que la lugareña", se creían disminuidos por tener una obra en ciudades provinciales y los comparó con los artistas franceses o italianos, quienes, según él, no protestaban frente a la misma situación en sus respectivos países; al contrario, se sentían muy honrados, "son ciudadanos que tienen plena conciencia de la nacionalidad cuya esencia no trasunta tan solo en la urbe capital" (1942, pp. 179-180).

En defensa de los artistas, Mario A. Canale, en esta oportunidad como presidente de la Corporación de Artistas Plásticos ${ }^{26}$, si bien no se refería específicamente a este programa, sostenía que "cuando un artista tiene una o dos obras y se la manda a un Museo lejano" se le quitaba "toda figuración” y se lo hacía "desaparecer, por este hecho, de entre los artistas representativos" 27 . Estimamos que sus apreciaciones revelaban el principal motivo de disconformidad de los artistas premiados: el alejamiento de los lugares de consagración que implicaba este programa de difusión artística. Para ellos, era un obstáculo más que venía a sumarse a la dispersión patrimonial que había comenzado el MNBA con los préstamos fundacionales, otro programa que hacía peligrar la posibilidad de que sus obras se exhibieran en sus salas, un espacio de visibilidad importante en la trayectoria de todos los artistas.

En relación a esto último, Canale agregaba que con este programa se les faltaba el respeto a aquellas personas que, "con una actitud patriótica", habían legado sus colecciones al acervo del MNBA. Con esta acción, se torcía la voluntad de los donantes ya que

no puede compararse el valor de exhibición en el Museo Nacional con un museo de provincia, donde se cuentan días sin tener un solo visitante. Si la voluntad del donante fuera contribuir a esos museos del interior, no necesitarían intermediarios, pues lo harían directamente ${ }^{28}$.

\footnotetext{
${ }^{24}$ Germán de Elizalde, Enrique Farías Velloso y Gonzalo Leguizamón Pondal.

${ }^{25}$ CMBA de Pergamino (25 de septiembre de 1936). Libro de Actas. Ob. cit.

${ }^{26}$ La Corporación de Artistas Plásticos se fundó en diciembre de 1932 y comenzó sus actividades en marzo del mes siguiente. Tenía como objetivos controlar las gestiones de la DNBA, proponer medidas para la comunidad artística y promover la difusión artística en la capital y el resto del país. En Momento Plástico, 1 de abril de 1933, p.3.

${ }^{27}$ Canale, M. A. (23 de enero de 1935). Carta al Director Nacional de Bellas Artes, Ing. Nicolás Besio Moreno, Buenos Aires. Archivo Schiaffino - AGN.

${ }^{28}$ Canale, M. A. (23 de enero de 1935). Carta al Director Nacional de Bellas Artes, Ing. Nicolás Besio Moreno, Buenos Aires. Archivo Schiaffino - AGN.
} 
Sus palabras dejaban en evidencia la desvalorización que existía hacia las instituciones provinciales, ligada, en este caso, a la (supuesta) casi nula concurrencia a las mismas. A cambio, sugería que se enseñara a las comisiones de bellas artes el ejemplo del MNBA, que con "ayuda del gobierno y la generosidad privada" había conseguido formar su colección. Proponía que se vuelquen a gestionar dinero de sus municipios, de las grandes empresas y de los vecinos acaudalados y así lograrían "adquirir obras a los artistas que tanto necesitan"29. Eduardo Schiaffino, ex director del MNBA, fue un aliado en esta cruzada. Por esos años escribía en el diario La Fronda artículos sobre arte y también sus opiniones sobre el rumbo que había tomado el MNBA. Allí expresó su disgusto por la organización de las salas, las adquisiciones de obras y el desmembramiento de la colección patrimonial que estaba llevando adelante Atilio Chiáppori. Asimismo, cuestionaba el merecimiento de las nóveles instituciones para recibir la asistencia del Nacional, ya que consideraba que sus "vecindarios no han hecho el menor esfuerzo en forma de legados, suscripciones públicas, donación de edificios, etc., para merecer una ayuda que, cumplido ese requisito, sería justificada" ${ }^{30}$. Preocupado por el destino de las obras, sobre todo de aquellas que habían sido donadas, se preguntaba

Con qué criterio se hacen las selecciones para remitir las unas al Museo Histórico, las otras al Etnográfico, y las demás a incipientes Museos de provincia o de campaña, o se las sepulta en el limbo del depósito? Acaso la arbitrariedad cuando es absoluta se transforma en clarividencia? ${ }^{31}$

Mario A. Canale ${ }^{32}$, por su parte, desde las páginas de la revista Momento Plástico se encargó de remarcar el peligro que corría el patrimonio del MNBA, frente a la gran la cantidad de obras que repartía. Además, advertía que la DNBA hacía cumplir al "Museo Nacional un plan de difusión cultural que no le corresponde" y que tampoco cumplía con la finalidad que tienen las instituciones de este tipo:

Todo Museo, por su naturaleza, es eminentemente conservador en el sentido de guardar su patrimonio y enriquecerlo, solo el Museo Nacional de Bellas Artes adapta la política original de deshacerse de sus obras prestándolas - con autorización de la Dirección Nacional - lo que está en pugna con el decreto de su creación. La Dirección Nacional de Bellas Artes, si desea desarrollar su plan de difusión cultural ayudando a los museos del interior, que lo haga en buena hora, pero, sin tocar para

\footnotetext{
${ }^{29}$ Canale, M. A. (23 de enero de 1935). Carta al Director Nacional de Bellas Artes, Ing. Nicolás Besio Moreno, Buenos Aires. Archivo Schiaffino - AGN.

${ }^{30}$ Schiaffino Eduardo (24 de mayo de 1934). El derrumbe de una noble institución. La Fronda.

${ }^{31}$ Schiaffino Eduardo (24 de mayo de 1934). El derrumbe de una noble institución. La Fronda.

${ }^{32}$ Schiaffino guardó copia de la nota que Canale envió a Nicolás Besio Moreno, director de la DNBA, y el borrador de la nota que publicó en el diario La Prensa, el 2 de febrero de 1935, contestando las declaraciones de Atilio Chiáppori en La Nación, [23 de enero de 1935], en relación a su gestión en el MNBA. Archivo Schiaffino - AGN, Buenos Aires.
} 
nada el acervo del Museo Nacional ${ }^{33}$.

Por otro lado, el ya mencionado Alberto Prebisch y el artista Emilio Pettoruti ${ }^{34}$, se encargaron de desprestigiar los conjuntos de obras que se enviaban al "interior" poniendo en discusión la calidad de las mismas. El primero, calificó a los envíos como "desechos" del MNBA, haciendo foco en que las obras provenían de la reserva del MNBA(Chiáppori, 1942, p. 178). Por su parte, Pettoruti, cuando asumió la dirección del Museo Provincial de Bellas Artes de La Plata, devolvió las obras que el MNBA le había cedido en 1928 "porque eran de calidad mediocre" y agregaba que "con un criterio poco didáctico nuestra primera pinacoteca enviaba a los museos obras que no exhibía por malas deformando así la visión de los públicos de tierra adentro" (1968, p. 226).

Chiáppori también defendió este programa, argumentando que el depósito era el único recurso al que podían apelar, pero que ese hecho no significaba que fuesen "desechos". Sostenía que, si eso fuese cierto, "las clases cultas" de Córdoba, Rosario, Santa Fe y Paraná, no seguirían solicitando telas del patrimonio nacional (1942, pp. 176-178). Como señaló Herrera (2012, p. 532) los reiterados pedidos, desde los años cuarenta, para recuperar los conjuntos prestados, refuerzan la idea sobre importancia de esas obras.

Entonces ¿qué tipo de obras se pusieron en circulación? ¿Cómo estaban compuestos los préstamos? ¿Qué intenciones existía detrás de cada conjunto en préstamo? A continuación, nos ocupamos de responder estas preguntas, analizando la composición de los envíos que el MNBA concretó a las ciudades de Bahía Blanca y San Nicolás en 1933 y de Tandil en 1936, las primeras localidades bonaerenses que buscaron fundaron sus propios museos de arte.

\section{La colección del MNBA y los envíos fundacionales}

A medida que fue avanzando el siglo XX, el arte argentino fue ganando terreno en la colección del MNBA y en el mercado de arte porteño. Los premios-adquisición del Salón Nacional de Bellas Artes y los efectos de la crisis económica mundial de 1929 habían convertido al arte local en la opción más accesible para la compra y además ofrecía menos dudas respecto a su autenticidad (Baldasarre, 2013, p. 256). En este contexto, el MNBA relegó paulatinamente su preferencia por el arte europeo e incorporó producciones nacionales, muchas de las cuales fueron las que se enviaron a otras ciudades con los préstamos fundacionales. Nos interesa precisar entonces la proporción que tuvo el arte argentino en los préstamos que envió el MNBA a las ciudades bonaerenses de Bahía Blanca, Tandil y San Nicolás; comparar la composición de cada uno de ellos, establecer las características presentes a lo largo de esta práctica y determinar si existía un interés real por difundir las producciones plásticas legitimadas desde la capital o si la motivación de fondo era instalar un criterio expositivo "a imagen y semejanza" del Nacional (Figura 5).

\footnotetext{
${ }^{33}$ Canale, M. A. (abril de 1933). Op. cit.

${ }^{34}$ Emilio Pettoruti (1892-1971) fue director del Museo Provincial de Bellas Artes de La Plata entre 1931 y 1947.
} 
Basualdo. Políticas estatales para las instituciones y el arte argentino en los años '30.

Figura 5. Cantidad de obras del MNBA enviadas en los préstamos fundacionales a las ciudades bonaerenses

\begin{tabular}{lccccc}
\hline \multicolumn{1}{c}{ Envío MNBA } & $\begin{array}{c}\text { Bahía Blanca } \\
1933\end{array}$ & $\begin{array}{c}\text { San Nicolás } \\
1933\end{array}$ & $\begin{array}{c}\text { Tandil } \\
1936\end{array}$ & $\begin{array}{c}\text { Bahía Blaca } \\
1936\end{array}$ & \multirow{2}{*}{ Total } \\
\hline Obras argentinas & 21 & 17 & 7 & 6 & 51 \\
\hline Obras españolas & 1 & 5 & 7 & 1 & 14 \\
\hline Obras francesas & 2 & 7 & 2 & 1 & 12 \\
\hline Otros & 4 & 10 & 4 & - & 18 \\
\hline Total & 28 & 39 & 20 & 8 & 95 \\
\hline
\end{tabular}

Fuente: Elaboración propia.

En primer lugar, resaltamos que la presencia del arte argentino fue cuantitativamente importante en todos esos préstamos. Esta característica estuvo presente desde los primeros envíos, a principios de siglo XX. Agüero (2017, p. 270) señaló que, por ejemplo, más de la mitad de las obras enviadas al Museo de Córdoba en 1914, correspondían a artistas argentinos vivos, replicando la tendencia coleccionista del MNBA. Pero, en 1931 recibió otro conjunto donde había un predominio de escuela francesa contemporánea, en su mayoría paisajes (Herrera, 2014, pp.544-545), el cual, como veremos, tuvo una composición excepcional en comparación a los que se realizaban por la misma década.

El primer préstamo para el Museo de Bahía Blanca, en 1933, estuvo conformado por veintiocho obras ${ }^{35}$ : veintidós eran de artistas argentinos, en su mayoría adquiridas en el Salón Nacional. Las extranjeras habían ingresado de diverso modo al MNBA. Varias de ellas eran representativas de su período fundacional, tales como: el óleo del español Justo Ruiz Luna provenía de la colección de Aristóbulo Del Valle ${ }^{36}$, la obra del francés Louis J. R. Collin, había sido comprada por Eduardo Schiaffino en 1906, durante su viaje a Europa ${ }^{37}$, y la del italiano Pietro Fragiacomo ${ }^{38}$ había sido adquirida en la Exposición Internacional del Centenario de 1910.

En relación con las firmas argentinas, estas estaban directamente vinculadas con los premios del Salón Nacional y de otros concursos oficiales. Las temáticas que primaban eran las que allí se distinguían: los tradicionales paisajes, los retratos y las escenas costumbristas. Entre los primeros encontramos firmas como las de Felipe Troilo, Bernaldo de Quirós y escenas boquenses de la mano de Lucas Albino y Ceferino Carnacini. Había, también, obras de carácter nativistas como la de Demetrio Iramain, Bajando a la fiesta, y la de Alfredo Gramajo Gutiérrez, El responso. Estas se contraponían a escenas modernas habitadas por personajes desafiantes, como el óleo De visita de Raúl

${ }^{35}$ Listado de obras corroborado con el departamento de Documentación del MNBA, obtenido de: "El Museo Municipal de Bellas Artes de Bahía Blanca" en La Prensa, 27 de julio de 1933. Archivo Cabré Moré, Biblioteca Popular Bernardino Rivadavia, Bahía Blanca.

${ }^{36}$ La obra de Justo Ruiz Luna (1865-1926), Restos de naufragio, 1887, óleo sobre tela, 151,5 x $351 \mathrm{~cm}$. Premio de honor en la Exposición Nacional de Bellas Artes de Madrid. Colección MNBA. Sobre la colección de Aristóbulo del Valle ver Baldasarre, 2006.

${ }^{37}$ Louis J. R. Collin (1850-1916), Nonchalance, s.f., óleo sobre tela, 74 x $60 \mathrm{~cm}$. Colección MNBA.

${ }^{38}$ Pietro Fragiacomo (1856-1922), El mar, [1910], óleo sobre tela, 186 x $300 \mathrm{~cm}$. Colección MNBA. 
Mazza, En el estudio de Luis Emilio Radice, Martita de Hildara Perez de Llanso, donde las niñas interpelan al espectador con sus miradas inquietantes, y Retrato de Srta. D. W. de Miguel Petrone, donde una mujer envuelta en un tapado mira de manera provocadora en dirección fuera del cuadro. Los clásicos retratos vinieron de la mano de los escultores más prolíficos de la época: Retrato del pintor Vidal de Nicolás Antonio de San Luis, El poeta Alfredo Bufano de Agustín Riganelli y Cabeza de hombre de Luis Rovatti. En relación con el rango temporal, las obras comprendían un abanico que iba desde fines del siglo XIX hasta finales de la década del veinte. Pero, mientras las extranjeras eran más cercanas a los inicios del siglo XX (la obra más tardía era de Pedro Figari, c. 1923) las nacionales, se extendían hasta la década del veinte.

El segundo envío para el Museo de Bahía Blanca fue un complemento del anterior, compuesto por siete obras, continuando la misma tendencia: cinco eran de arte argentino contemporáneo y dos de artistas extranjeros; una correspondía al pintor español José Pinelo Llull y otra al francés Antoine Vollon ${ }^{39}$.

El conjunto que se destinó a San Nicolás fue de treinta y nueve obras, el más grande de los estudiados en este artículo ${ }^{40}$. En este caso, se revirtió la composición del envío a Bahía Blanca: menos de la mitad eran de artistas argentinos y solo dos provenían del Salón Nacional. Gran parte habían sido adquiridas directamente al autor, en remates u otras exposiciones, entre fines del siglo XIX y la década de 1920. Por mencionar algunos ejemplos, la escultura de Pedro Zonza Briano había sido adquirida al autor por el Ministerio de Justicia e Instrucción Pública en 1914 y el óleo de Justo Lynch en la galería Witcomb en 1926. Del total, las donaciones eran diez, algunas de las cuales era de la colección fundacional del MNBA, como las de Ángel Roverano y Adriano Rossi (Baldasarre, 2006). En cuanto a las firmas extranjeras, las francesas eran las más representadas, pero existía una variada procedencia de artistas: una obra del uruguayo Carlos Castellanos, otra del peruano José Sabogal y del italiano Ignacio Manzoni, entre otros. Las temáticas también eran variadas, aunque predominaron las figuras humanas, ya sea en retratos o en escenas regionales.

En relación con envío fundacional destinado a Tandil en 1936, el número de obras bajó considerablemente respecto del anterior: se destinaron veinte y tampoco las nacionales superaron a las extranjeras ${ }^{41}$. Solo siete se correspondían a las primeras e igualaban en cantidad a las pinturas españolas. La mayor parte de las obras extranjeras provenían del legado de Juana Blanco Casariego y Giraldez, legado que proporcionó gran cantidad de obras españolas al MNBA (Serventi y Galesio, 2014). Llamativamente, este legado se desmembró el mismo año que ingresó a la institución. Es importante señalar que tanto la presencia de obras españolas como la de artistas argentinos, no fueron prioridad durante estos años en las salas del MNBA. A lo largo de la gestión de Atilio Chiáppori (1931-1939) se organizaron cuatro exposiciones dedicadas al arte

\footnotetext{
${ }^{39}$ Listado de obras facilitado por el departamento de Documentación del MNBA.

${ }^{40}$ Listado de obras facilitado por el departamento de Documentación del MNBA.

${ }^{41}$ Listado de obras obtenido de Manochi, J. (1970, pp. 49-51) y corroborado con el departamento de Documentación del MNBA.
} 
francés ${ }^{42}$, una al arte español - organizada por la Asociación Amigos del Arte, Pintura española, de los primitivos a Rosales, en 1939 - y solo una al arte argentino, que se llamó Un siglo de arte en la Argentina, en 1936.

En relación con todo lo antedicho, nos interesa resaltar la ausencia de un criterio definido de artistas, de estilos o de alguna otra índole: los tres préstamos presentaban obras de diferente procedencia, nacionalidades y épocas. Además, es relevante advertir que solo en los préstamos destinados a Bahía Blanca la cantidad de obras nacionales superó a la suma de las obras extranjeras, mientras que, en los otros dos casos, la composición de los conjuntos estuvo armada con una mayoría de artistas que no eran del país. Esta diferencia, en parte, se explica por la inclusión de las donaciones fundacionales y de las compras realizadas en los primeros años de vida del MNBA, decisión que habilitó las discusiones que mencionamos anteriormente.

Asimismo, recordemos que, luego de la mudanza del MNBA a su edificio definitivo en 1933, se elaboró el inventario de obras y se reorganizaron los espacios con nuevos criterios de exhibición, de salas despojadas y austeras. Lo cual aumentó la cantidad de obras en reserva y, por lo tanto, la disponibilidad para los otros museos. De manera que, más que a un plan meditado, el armado de los envíos fundacionales parecía responder a lo que el depósito del MNBA podía proveer y que no era tenido en cuenta para exhibirse en sus salas.

\section{Reflexiones finales: "se hizo lo que se pudo"}

Los programas llevados adelante por el Estado Nacional, a través de sus respectivos organismos, demuestran el interés por difundir el arte argentino e incentivar el desarrollo de espacios artísticos locales de dependencia pública. Sin embargo, la intervención de la DNBA fue importante pero no suficiente para la creación y el sostenimiento de nuevas instituciones artísticas. La autocrítica de Chiáppori en relación con la puesta en práctica de las exposiciones viajeras citada como título para este cierre (1942, p.176), puede hacerse extensivo a todas las iniciativas que se impulsaron como política estatal para las actividades artísticas, donde gran parte de las limitaciones estaban dadas por el acotado presupuesto que manejaba el organismo nacional. Esto último, dio como resultado programas que carecían de un plan de acción definido. Al mismo tiempo, la DNBA aprovechó estas estrategias para afirmar su posición y marcar territorio frente a la proliferación de espacios artísticos en la capital del país y en otras ciudades provinciales. Como señaló Diana Wechsler "se trataba de ocupar efectivamente la mayor cantidad de lugares posibles, tanto los instituidos como aquellos de reciente creación" (1999, p. 73).

Por otro lado, las exposiciones con las obras del Salón Nacional fueron una importante posibilidad para los artistas locales de tomar contacto con los artistas

\footnotetext{
42 En noviembre de 1933, el MNBA alojó la exposición Un siglo de pintura francesa, en octubre de 1934 se exhibieron obras de Auguste Rodin, en 1936 tuvo lugar la muestra Pintura Moderna con obras de artistas franceses contemporáneos de la colección Rafael Crespo y en julio de 1939, La Pintura Francesa, de David a nuestros días.
} 
consagrados, funcionando como una herramienta pedagógica. Para la mayoría de los artistas provinciales, el SNBA aún era un espacio al que llegar, y estas exposiciones servían como guía acerca del rumbo que iba tomando la producción plástica oficial; así, el día de mañana, abrigarían mayores posibilidades de acceder a la competencia más importante a nivel nacional. Luego, las instituciones nacionales, con el filtro de la premiación, volverían a esos rincones provincianos para continuar con la tarea de instalar un determinado canon, que no se aceptaría acríticamente ni en la capital ni en las otras ciudades.

Sostenemos, entonces, que la implementación de estos programas - de la mano de las instituciones nacionales-guardaba el interés de hacer de estas nuevas e incipientes instituciones artísticas espacios de legitimación para la creciente circulación de arte argentino, pero no con un interés genuino en crear condiciones efectivas para activar o fortalecer el desarrollo del campo local. En este sentido, mientras las exposiciones viajeras dieron a conocer las producciones plásticas argentinas contemporáneas y los "envíos fundacionales" fueron las herramientas más efectivas para dar origen a nuevos museos o sostenerlos, las producciones de los artistas locales no fueron contempladas por ninguno de estos u otros programas. Así, en cada localidad, la decisión de visibilizar o no a sus artistas, desató otros conflictos, algunos de los cuales se relacionaron con el lugar de consagración por excelencia que significaba la capital nacional.

\section{Fuentes}

Besio Moreno, N. (septiembre y octubre de 1934). Propiciase la creación de comisiones de bellas artes en el interior. En Boletín del Museo Nacional de Bellas Artes.

Canale, M. A. (abril de 1933). Los miembros de la Dirección Nacional de Bellas Artes deben ser técnicos. En Momento Plástico, $\mathrm{n}^{\circ}$ 1, año 1, p. 1.

Canale, M. A. (23 de enero de 1935). Carta al Director Nacional de Bellas Artes, Ing. Nicolás Besio Moreno, Buenos Aires. Archivo Schiaffino - AGN.

Canale, M. A. (s.f.). Sobre las salidas de obras del Museo Nacional de Bellas Artes. Contestando un reportaje. Archivo Eduardo Schiaffino, AGN.

CMBA de Pergamino (1936-1940). Libro de Actas. Escuela Municipal de Bellas Artes. Archivo del Museo Municipal de Artes Plásticas "Manuel Belgrano" de Pergamino.

Dirección Nacional de Bellas Artes (septiembre y octubre de 1934). Boletín del Museo Nacional de Bellas Artes, p. 20-21.

DNBA, (1 de septiembre 1931 - 8 de marzo 1938). Cuarta época. Archivo Palais de Glace, Buenos Aires.

Exposición de obras del Salón Nacional (1 de enero de 1935). La Nueva Provincia, Bahía Blanca.

Martínez Granados, E. (8 de noviembre de 1938). Consideraciones con respecto al V Salón Municipal de Bellas Artes. La Opinión, Pergamino. 
Ministerio de Justicia e Instrucción Pública (1934). Museos y Comisiones de Bellas Artes del Interior. En: Dirección Nacional de Bellas Artes. Organización y funcionamiento, Buenos Aires, p. 15. Biblioteca Nacional Mariano Moreno.

Museos. Primera conferencia del ciclo, auspiciada por la Asociación Amigos del Museo, a cargo del Arq. Alberto Prebisch. Octubre 18 de 1934 (septiembre y octubre de 1934). Boletín del Museo Nacional de Bellas Artes, p. 2-7.

Museo de Bellas Artes, Palacio Municipal, Río Cuarto, Exp. Cat. diciembre-enero. Archivo Fundación Espigas, Buenos Aires.

Schiaffino Eduardo (24 de mayo de 1934). El derrumbe de una noble institución. La Fronda. Se exhibirán en varias provincias los premios del XXV Salón Anual (10 de octubre de 1935). La Nación.

Una muestra de arte se realizará en Mar del Plata (4 de febrero de 1937). La Capital, Mar del Plata.

Uriburu, J. F. (1 de septiembre de 1931). Exp. M. 144/1931 [decreto de creación de la DNBA]. Ministerio de Justicia e Instrucción Pública. Archivo Palais de Glace, Buenos Aires.

\section{Referencias bibliográficas}

Agüero, A. C. (2017). Local / Nacional. Una historia cultural de Córdoba en el contacto con Buenos Aires (1880 - 1918). Buenos Aires: Universidad Nacional de Quilmes Editorial, Cap. IV.

Baldasarre, M.I. (2011). "El surgimiento del mercado de arte y la profesionalización de los artistas en la Argentina". En Baldasarre, M. I. \& Dolinko, S. (ed.). Travesías de la imagen. Historia de las artes visuales en la Argentina (pp. 235-263). Buenos Aires: Eduntref, vol. I.

Baldasarre, M.I. (2013). "Museo universalista y nacional. El lugar del arte argentino en las primeras décadas de vida institucional del Museo Nacional de Bellas Artes de Buenos Aires". En A Contra corriente, vol.10, n 3, p.255-278.

Baldasarre, M.I. (2006). Los dueños del arte. Coleccionismo y consumo cultural en Buenos Aires. Buenos Aires: Edhasa. Ballent, A. \& Gorelik, A. (2001). "País urbano o país rural: la modernización territorial y su crisis". En Cattaruzza, A. (dir.), Nueva Historia Argentina. Crisis económica, avance del Estado e incertidumbre politica (1930 - 1943). Buenos Aires: Sudamericana, tomo 7. Cap. IV.

Bourdieu, P. (1990). "Algunas propiedades de los campos". En Sociología y cultura. México D. F.: Grijalbo.

Cattaruzza, A. (2001). "Descifrando pasados: debates y representaciones de la historia nacional". En Nueva Historia Argentina. Crisis económica, avance del Estado e incertidumbre politica (1930 - 1943). Buenos Aires: Sudamericana, tomo 7. Cap. X.

Chiáppori, A. (1942). Luz en el templo. Buenos Aires: Ministerio de Justicia e Instrucción Pública.

Herrera, M. J. (2014). Cien años de arte argentino. Buenos Aires: Editorial Biblos. 
Herrera, M. J. (2012). "El Museo Nacional de Bellas Artes y su proyección nacional, 1911- 1943”. En Baldasarre, M.I. \& Dolinko, S. (ed.), Travesías de la imagen. Historia de las artes visuales en la Argentina, (pp. 529-552). Buenos Aires: Eduntref, vol. II.

Fasce, P. (2017). El noroeste y la institucionalización de las artes en Argentina: tránsitos, diálogos y tensiones entre región y nación (1910-1955) (Tesis de doctorado). Recuperado de https://ri.unsam.edu.ar/xmlui/handle/123456789/758

Gutiérrez Viñuales, R. (2004). "Arte y vida académica en la Argentina. Vicisitudes de una experiencia tardía". En Tiempos de América. Castellón, n 11, pp. 105-113.

Manochi, J. (1970). Tandil en el arte. Una contribución a la historia del arte argentino. Cómo nació y se desarrolló el Museo y Academia Municipal de Bellas Artes de Tandil. Buenos Aires: Instituto Salesiano de Artes Gráficas.

Pettoruti, E. (1968). Un pintor ante el espejo. Buenos Aires: Solar / Hacette.

Podgorny, I. (2005). "La mirada que pasa: museos, educación pública y visualización de la evidencia científica”. En História, Ciências, Saúde - Manguinhos. Río de Janeiro, v. 12 (suplemento), p. 231-64.

Serventi, M. C., \& Galesio, M. F. (2014). Pintura española en el Museo Nacional de Bellas Artes. Catálogo. Buenos Aires: Lázara.

Suasnábar, M. G. (2013). Arte y sociedad en Tandil: el desarrollo de la Sociedad Estímulo de Bellas Artes y la creación del Museo Municipal, 1916-1938 (Tesis de maestría). Recuperado de: https://ri.unsam.edu.ar/xmlui/handle/123456789/869

Wechsler, D. (1998). "Nuevas miradas, nuevas estrategias, nuevas contraseñas". En Wechsler, D. (coord.), Desde la otra vereda. Momentos en el debate por un arte moderno $(1880$ - 1960) (pp. 120-155). Buenos Aires: CAIA, Ediciones del Jilguero.

Wechsler, D. (1999). "Salones y contra - salones". En Penhos, M., \& Wechsler, D. (coord.). Tras los pasos de la norma. Salones Nacionales de Bellas Artes (1911 1989). Buenos Aires: Archivos del CAIA 2, Ediciones del Jilguero. 